\title{
Issues of Estimating the Quality of the Facilities Management of the Emercom of Russia at the Elimination of the Emergency Situations Consequences
}

\author{
Valeriy Borisovich Vilkov ${ }^{1 *}$, Andrey Kliment'evich Chernykh ${ }^{2}$, Alexander Alekseevich Tarantsev², Yuri \\ Evgenievich Aktersky', Ilya Danilovich Cheshko ${ }^{2}$ \\ ${ }^{1}$ Federal Public State Military Educational Institution of the Higher Education "Military academy of material support of general A.V. \\ Hrulyov" of the Ministry of Defence of the Russian Federation, Makarova Emb., 8, Saint-Petersburg, 199034, Russia \\ ${ }^{2}$ Saint-Petersburg university of State fire service of EMERCOM of Russia, Moskovsky Ave., 149, Saint-Petersburg, 196105, Russia \\ *Corresponding author E-mail: v_b_vilkov@mail.ru
}

\begin{abstract}
The article deals with the problem of multiobjective optimization with regard to the decision making on the use of the forces and facilities of the EMERCOM of Russia (Ministry of the Russian Federation for Affairs for Civil Defence, Emergencies and Elimination of Consequences of Natural Disasters). The purpose of the article is to create a method for prompt and reasonable calculations when making a decision on the use of the EMERCOM forces and facilities to eliminate the consequences of emergency situations. The proposed method uses fuzzy sets, fuzzy logic, and the Mamdani fuzzy inference algorithm. The work gives a substantial example illustrating the application of the mentioned theory to solve the problem of choosing the optimal version of the task performed by the facilities of the EMERCOM of Russia. Regarding the novelty, it should be noted that the quality characteristics of the solutions are fuzzy and not unambiguously defined, and therefore allow applying the effective mathematical apparatus of fuzzy sets theory, fuzzy logic and the Mamdani fuzzy inference algorithm in solving this problem.
\end{abstract}

Keywords: elimination of consequences of emergencies, efficiency criteria, fuzzy set, fuzzy logic, linguistic variable, an optimal variant for task accomplishment, membership function.

\section{Introduction}

In the process of making a decision to use the facilities of EMERCOM of Russia during the elimination of the consequences of emergency situations, it is often necessary to choose the optimal variant of the task accomplishment. If the variant quality is estimated using a single efficiency criterion, then the solution of this problem may turn out to be very complicated (even unsolvable). However, the solution principle would be to choose an option with the optimal efficiency criterion value. When several efficiency criteria are used, the concept of optimality becomes indefinite, since it is not always clear which option is preferable. The task solution option which is the best from the point of view of some criteria can turn out to be very bad according to other criteria. Problems of this type belong to the class of problems of vector (multiobjective) optimization [1-5]. The solution of these tasks essentially depends on the specific nature of the subject area and is connected with certain methodological difficulties, which, in our opinion, gives an obvious relevance to the effective solution of the problem formulated in the article.

Formulate a verbal statement of the problem under consideration. We have many variants $V=\{u, v, t, \ldots\}$. We also have several functions $f_{1}(u), f_{2}(u), \ldots, f_{k}(u)$, with definition range of the set $V$. These functions are called partial criteria. Consider the vector criterion $F(u)=\left(f_{1}(u), f_{2}(u), \ldots, f_{k}(u)\right)$. It is required to choose in the set $V$ a variant, which is the best in the matter of the vector criterion $F(u)$.

One of the approaches to solving this problem is based on the fact that by using a certain function $k$ of variables, the vector criterion is convoluted and the transition to a problem with one criterion is implemented. Consider a function $G\left(x_{1}, x_{2}, \ldots, x_{k}\right)$. With this function it is possible to pass to one criterion $H(u)$ by carrying out a convolution of the vector criterion according to the formula:

$H(u)=G\left(f_{1}(u), f_{2}(u), \ldots, f_{k}(u)\right)$

There are different ways of constructing convolutions. In this paper is used a method based on the theory of fuzzy sets and fuzzy logic and used, for example, in [6].

The theory of fuzzy sets dates back to 1965, when Professor Lotfi Zadeh [7] from the University of California, Berkeley published the fundamental work "Fuzzy Sets". The concept of a fuzzy set was arisen by Zadeh [7] due to "dissatisfaction with mathematical methods of the classical theory of systems, which forced to achieve artificial accuracy, inappropriate in many real-world systems, especially in so-called humanistic systems involving people." In the eighties of the last century, Bart Kosko proved the fuzzy approximation theorem, according to which any mathematical system can be approximated by a system based on fuzzy logic. 
Systems based on fuzzy sets have been developed and successfully implemented in such areas as process management, transport management, medical diagnostics, technical diagnostics, financial management, stock forecasting, pattern recognition. Practical experience in the development of fuzzy inference systems shows that the time and costs spent for their development are much less than for using a traditional mathematical apparatus, while the required level of stability against model uncertainties and model transparency is ensured.

The above-mentioned, from our point of view, proves the relevance of the method proposed in the article for solving the problem stated, which is based on the theory of fuzzy sets and fuzzy logic.

Without loss of generality, let us use two particular criteria due to the fact that this situation is important for the process of informational support for the development of decisions - the use of the facilities of the EMERCOM of Russia within the framework of the task. Here, the decision-maker solves the problem of maximizing the operational criterion, while minimizing the importance of the economic criterion (the cost of the task accomplishing). It is obvious that these requirements are contradictory, and this creates difficulties in the process of elaborating these decisions [6].

\section{Methods}

Let us introduce the necessary definitions [8-10]. A fuzzy set $\hat{A}$ on a universal set $U$ is a collection of pairs $\left(\mu_{\hat{A}}(u), u\right)$, where $\mu_{\hat{A}}(u)-$ is the membership function, which indicates the membership degree of an arbitrary element of the universal set to a fuzzy set $\hat{A}$. The degree of membership (reliability) is a number from the interval $[0 ; 1]$. The higher the membership degree, the more the element of the universal set corresponds to the properties of the fuzzy set.

The intersection of fuzzy sets $\hat{A}$ and $\hat{B}$ given on $U$ is a fuzzy set $\hat{C}=\hat{A} \cap \hat{B}$ with a membership function

$\mu_{\mathrm{C}}(\mathrm{u})=\min \left\{\mu_{\hat{\mathrm{A}}}(\mathrm{u}), \mu_{\hat{\mathrm{B}}}(\mathrm{u})\right\}$ for all $\mathrm{u} \in \mathrm{U}$.

The union of fuzzy sets $\hat{A}$ and $\hat{B}$ given on $U$ is a fuzzy set $D=\hat{A} \cup$ $B$ with a membership function

$\mu_{\hat{D}}(u)=\max \left\{\mu_{\hat{A}}(u), \mu_{\hat{B}}(u)\right\}$ for all $u \in U$.

Following $[8,11,12]$, let us introduce some concepts of fuzzy logic. In classical mathematical logic, the values of statements can be only "true" or "false", with the value "true" corresponding to the figure 1, the value "false" - to the figure 0. Fuzzy logic considers fuzzy statements that may be true or false to some extent. The degree of truth of a fuzzy statement takes values from the closed interval $[0 ; 1]$, with 0 corresponding to the value "false", 1 - "true".

Denote the fuzzy variables of the statement of the form " $u$ and is an element of the fuzzy set $\tilde{A}$ " through $\tilde{A}$, while a membership function that specifies the truth values of this variable utterance, through $\mu_{\tilde{A}}(u), u \in[0,1]$.

On the fuzzy statements, various logical operations are defined. Let us focus on two of them, which are necessary for further study.

Denote fuzzy logical statements as $\tilde{A}$ and $\tilde{B}$, and the membership functions that define the truth values of these variables as $\mu_{\tilde{A}}(u)$ and $\mu_{\tilde{B}}(u), u \in[0,1]$. Fuzzy logical operations $\wedge$ (AND) and $\vee$ (OR) by analogy with set-theoretic operations, union and intersection are performed according to the rules:

$$
\begin{aligned}
& \mu_{\tilde{A} \wedge \tilde{B}}(u)=\min \left\{\mu_{\tilde{A}}(u), \mu_{\tilde{B}}(u)\right\}, \\
& \mu_{\tilde{A} \vee \tilde{B}}(u)=\max \left\{\mu_{\tilde{A}}(u), \mu_{\tilde{B}}(u)\right\} .
\end{aligned}
$$

Note that in the fuzzy logic a linguistic variable is a variable whose values can be words or phrases of some natural or artificial language.

A term-set is the set of all possible values of a linguistic variable, a term - any element of a term-set. Note that in the fuzzy sets theory the term is formalized by a fuzzy set using the membership function. Quite often, terms are formalized using triangular fuzzy numbers.

A triangular fuzzy number $A$ is a triple $\langle a ; b ; c\rangle, a \leq b \leq c$ of real numbers through which its membership function $\mu_{A}(u)$ is defined as follows:

$$
\mu_{A}(u)=\left\{\begin{array}{r}
\frac{u-a}{b-a}, \text { if } u \in[a, b], \\
\frac{u-c}{b-c}, \text { if } u \in[b, c],
\end{array}\right.
$$$$
0 \text {, else. }
$$

The second number $b$ of the triple $\langle a ; b ; c\rangle$ is usually called the mode or the clear value of the fuzzy triangular number. Numbers $a$ and $c$ characterize the degree of fuzziness (uncertainty) of a clear number (Figure 1).

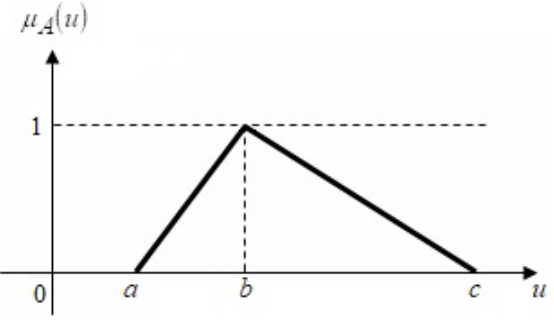

Fig. 1: Triangular number

An important role in the information support problems' solving for the management of the forces and facilities of the EMERCOM of Russia has a task in which it is required to determine the value of the indicator (output variable) $x_{1}, x_{2}, \ldots, x_{n}$ from the specified values of the parameters (input variables) $y(X)$. To solve it, the following algorithm is used [13-17].

1. From the given values of the parameters, determine their membership degree to different terms of the corresponding linguistic variables.

2. Using a fuzzy knowledge base and definitions of operations on fuzzy sets (terms), determine the membership degree of possible values of the indicator to a fuzzy set.

3. Using the resulting fuzzy set, perform its defuzzification, i.e. convert the fuzzy set into a clear number.

A fuzzy knowledge base on the influence of a given set of parameter values $X=\left(x_{1}, x_{2}, \ldots, x_{n}\right)$ on the value of an indicator $y(X)$ is the set of logical statements of the type: IF

$$
\left(x_{1}=a_{1}^{j_{1}^{1}}\right) A N D\left(x_{2}=a_{2}^{j_{2}^{1}}\right) \operatorname{AND} \ldots \mathrm{AND}\left(x_{n}=a_{n}^{j_{n}^{1}}\right)
$$

OR

$$
\left(x_{1}=a_{1}^{j_{1}^{2}}\right) \mathrm{AN} D\left(x_{2}=a_{2}^{j_{2}^{2}}\right) \mathrm{A} N D \ldots \mathrm{AN} D\left(x_{n}=a_{n}^{j_{n}^{2}}\right)
$$

OR

OR

$\left(x_{1}=a_{1}^{j_{1}^{k_{j}}}\right) \operatorname{AND}\left(x_{2}=a_{2}^{j_{2}^{k_{j}}}\right) \operatorname{AND} \ldots \mathrm{AND}\left(x_{n}=a_{n}^{j_{j_{n}}^{k_{j}}}\right)$

THEN $y(X)=d_{j}$, where $a_{i}^{j_{l}^{p}}$ - a fuzzy term, which evaluates the variable $x_{i}$ in the line with the number $p\left(p=1, k_{j}\right) ; j_{l}^{p}$ - a counting number of this 
term in the term-set of the linguistic variable with the number $l$, $j_{l}^{p}=\left\{1,2, \ldots, r_{l}\right\}, r_{l}$ - the number of elements in this term-set;

$k_{j}$ - the number of line-conjunctions, in which the indicator $y(X)$ is estimated by a fuzzy term $d_{j}$;

$m$ - the number of terms used for the linguistic evaluation of the output $y(X)$ with operations AND $\wedge$ and OR $\vee$

A fuzzy knowledge base can be rewritten in a more compact form:

$\bigvee_{p=1}^{k_{j}}\left[\wedge_{i=1}^{n}\left(x_{i}=a_{i}^{j_{i}^{p}}\right)\right] \Rightarrow y(X)=d_{j}, j=1,{ }^{-}$

A fuzzy knowledge base is often convenient to be specified in the form of a table.

Formula (4) allows us to build a fuzzy set "the value of the indicator $y(X)$ under a number the values of parameters $X$ " on the universal set of terms of the output linguistic variable.

The membership function of a fuzzy set formalizing the output term (term of the exponent) $d_{j}$ is denoted by $\mu_{d_{j}}(u)$. Its values are determined by the formula (3) with the values $a, b, c$. corresponding to the term $d_{j}$.

The membership function of a fuzzy set " $y(X)=d_{j}$ under the condition that the set of parameter equals $X^{\prime \prime}$ will be denoted $\bar{\mu}_{d_{j}}(X)$. Note that the universal set on which this function is defined is the set of all possible sets of values of the parameters. From (1), (2), and (4) follows that

$\bar{\mu}_{d_{j}}(X)=\max _{1 \leq p \leq k_{j}}\left[\min _{1 \leq i \leq n} \mu_{a_{i}^{j_{i}^{p}}}\left(x_{i}\right)\right]$.

The membership function $\mu_{y, X}(u)$ of a fuzzy set "the value of the indicator $y(X)$ under the collection of parameter values $X$ " is defined by the formula:

$\mu_{y, X}(u)=\max _{1 \leq j \leq m} \min \left\{\bar{\mu}_{d_{j}}(X), \mu_{d_{j}}(u)\right\}$,

where $u \in\left[y_{\min }, y_{\max }\right]$, and $y_{\min }, y_{\max ^{-}}$the minimum and maximum values of the indicator $y(X)$ respectively.

\section{Results}

To illustrate the theory given in the article, let us consider the following problem of choosing the optimal variant of the task solution to use the forces and means of the EMERCOM of Russia To accomplish this task, the EMERCOM must move to the operational destination by any transport. The effectiveness of the choice will be assessed using two performance indicators "operational efficiency" and "economic efficiency" (two linguistic variables). Consider the technology of obtaining the solution quality assessment for the application of this unit. If such estimates are obtained for all possible options, then to select the best one, we must solve the problem with one criterion, maybe even approximately (see, for example, [18-21]), which is much easier.

Terms for "operational efficiency" are: high $-B_{1}$, medium $-B_{2}$, low $-B_{3}$. Terms for "economic efficiency" (hereinafter understood as the financial costs of the task): very expensive - $A_{1}$, expensive - $A_{2}$, not very expensive $-A_{3}$, cheap $-A_{4}$.

Let the costs vary from the minimum value $\alpha$ to the maximum value $\beta$ depending on the decisions made. Then the costs associated with a particular solution will be equal $(1-\delta) \alpha+\delta \beta$, where $\delta$ - a number from zero to one. The set of values of $\delta$ will be considered as a universal set on which fuzzy sets are defined, formalizing the terms of the linguistic variable "economic efficiency".
The operational efficiency will be characterized by the probability $P$ of accomplishing the task. We will assume that this probability lies in the range from 0.5 to 0.98 . Then the universal set for terms of this variable is the interval $[0.5 ; 0.98]$.

These linguistic variables are called input, the linguistic variable "quality of solution" is output, let its terms are: unsatisfactory $C_{1}(2)$, satisfactory $-C_{2}(3)$, good $-C_{3}(4)$, excellent $-C_{4}(5)$. The universal set here is the interval $[2 ; 5]$.

For the terms of linguistic variables for the problem under consideration, the values of $a, b, c$ are indicated in Table 1 , the graphs of the distribution functions are given in Figures 2, 3 and 4. A fuzzy knowledge base is presented in Table 2 .

For example, if a decision is made with the economic efficiency "expensive", and the operational - "high", then according to Table 2 the quality of this solution has a fuzzy score 3 .

For the problem considered in the article, let us construct a clear estimate for the variant in which the linguistic variable "economic efficiency" has a value of 0.6 , and the probability of accomplishing the task is 0.9 .

Table 3 shows the values of membership functions, combinations (conjunctions) of terms of input linguistic variables for $\delta=0,6$ and $P=0,9$.

Table 1: Parameters of fuzzy triangular numbers formalizing the considered terms

\begin{tabular}{|c|c|c|c|c|}
\hline \multirow{2}{*}{} & \multicolumn{4}{|c|}{ Terms for the linguistic variable "operational efficiency" } \\
\cline { 2 - 5 } & low & medium & high & \\
\hline$a$ & 0,50 & 0,58 & 0,82 & \\
\hline$b$ & 0,56 & 0,74 & 0,98 & \\
\hline$c$ & 0,72 & 0,94 & 0,98 & \\
\hline \multirow{4}{*}{$a$} & \multicolumn{2}{|c|}{ Terms for the linguistic variable "economic efficiency" } \\
\cline { 2 - 5 } & cheap & not very expensive & expensive & very expensive \\
\hline$b$ & 0 & 0,19 & 0,50 & 0,75 \\
\hline$c$ & 0,19 & 0,42 & 0,70 & 1,00 \\
\hline \multirow{4}{*}{} & 0,44 & 0,62 & 0,90 & 1,00 \\
\cline { 2 - 5 } & Terms for the linguistic variable "quality of a solution" \\
\hline$a$ & 2,00 & satisfactory & good & excellent \\
\hline$b$ & 2,00 & 2,375 & 2,750 & 3,75 \\
\hline$c$ & 3,00 & 3,000 & 4,00 & 5,00 \\
\hline
\end{tabular}

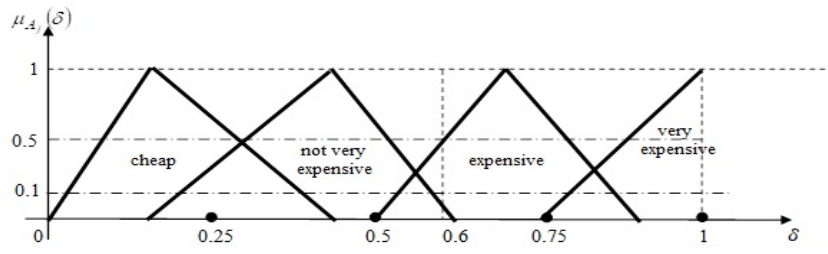

Fig. 2: The linguistic variable "economic efficiency"

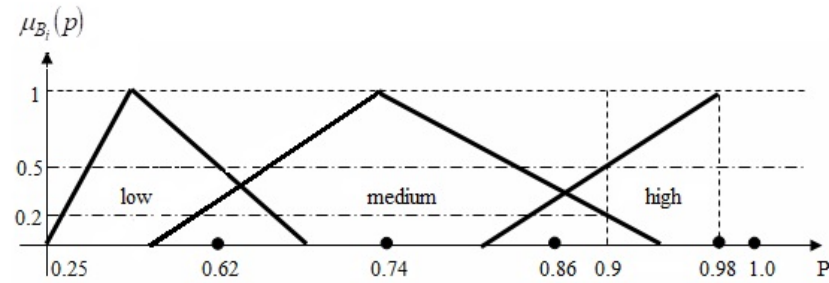

Fig. 3: The linguistic variable "operational efficiency"

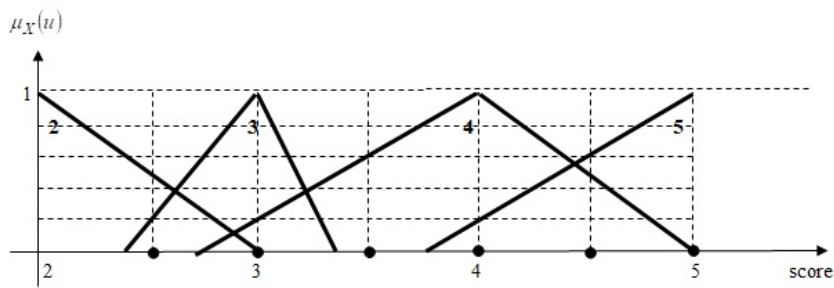

Fig. 4: The output linguistic variable 
Table 2: Fuzzy knowledge base

\begin{tabular}{|l|c|c|c|c|}
\hline & $\begin{array}{c}\text { Very } \\
\text { expensive } A_{1}\end{array}$ & $\begin{array}{c}\text { Expensive } \\
A_{2}\end{array}$ & $\begin{array}{c}\text { Not very } \\
\text { expensive } A_{3}\end{array}$ & $\begin{array}{c}\text { Cheap } \\
A_{4}\end{array}$ \\
\hline High $B_{1}$ & 2 & 3 & 4 & 5 \\
\hline $\begin{array}{l}\text { Medium } \\
B_{2}\end{array}$ & 2 & 2 & 2 & 4 \\
\hline Low $B_{3}$ & 2 & 2 & 2 & 2 \\
\hline
\end{tabular}

Table 3: The membership degree of the situation $\{\delta, P\}=\{0,6,0,9\}$ to

different combinations of the values of the input linguistic variables

\begin{tabular}{|c|c|c|c|c|c|}
\hline & $\mu_{B_{i}}(0,9)$ & $\begin{array}{c}\text { Very expensive } \\
A_{1}\end{array}$ & $\begin{array}{c}\text { Expensive } \\
A_{2}\end{array}$ & $\begin{array}{c}\text { Not very } \\
\text { expensive } A_{3}\end{array}$ & $\begin{array}{c}\text { Cheap } \\
A_{4}\end{array}$ \\
\hline$\mu_{A_{j}}(0,6)$ & - & 0 & 0,5 & 0,1 & 0 \\
\hline High $\mathrm{B}_{1}$ & 0,50 & 0 & 0,5 & 0,1 & 0 \\
\hline $\begin{array}{c}\text { Medium } \\
\mathrm{B}_{2}\end{array}$ & 0,20 & 0 & 0,2 & 0,1 & 0 \\
\hline Low $\mathrm{B}_{3}$ & 0 & 0 & 0 & 0 & 0 \\
\hline
\end{tabular}

The third row and the second column of Table 3 are filled according to the formula (3) using the data from Table 1 (based on the graphs of the membership functions of Figures 2 and 3). In other fields, the values of the membership function (truth) of the conjunctions of the corresponding terms of the input linguistic variables are indicated. These values are equal to the minimum of the values in the corresponding fields of the third row and the second column (formula (1)).

To obtain the reliability value (confidence level) of the output term for the considered variant of the input parameter values, it is necessary to take the maximum value from the reliability values indicated in Table 3 for this term (formula (5)). The results are shown in Table 4

Table 4: Reliability of output terms for the situation $\{\delta, P\}=\{0,6,0,9\}$

\begin{tabular}{|c|c|c|c|c|}
\hline Output terms & 2 & 3 & 4 & 5 \\
\hline Reliability & 0,2 & 0,5 & 0,1 & 0 \\
\hline
\end{tabular}

The maximum positive values of membership functions were obtained only for the first three terms. These values are obtained (see Table 3 ) for the variants $B_{2}-A_{2}, B_{1}-A_{2}, B_{1}-A_{3}$. Denote them $\mathrm{C}_{22}, \mathrm{C}_{12}, \mathrm{C}_{13}$ respectively.

Determine the membership degree of different indicator values (output variable) (with 0.5 increment) with combinations $\mathrm{C}_{22}, \mathrm{C}_{12}$, $\mathrm{C}_{13}$ of parameter values (see Table 5, lines $2-4$ ). For example, the membership degree of a numerical value of 2 to the term of the indicator is satisfactory $\left(C_{2}\right)$ and equals zero (see Figure 4); similarly, the membership degree of the numerical value 2.5 to the term of the indicator is satisfactory and equals 0.2 , etc. The following three lines give the membership degrees of different numerical values of the indicator (output variable), taking into account the membership degree of the corresponding combination of values (terms) of the parameters (see Table 3 ).

The last line of Table 5 shows the values of the fuzzy set membership function $\mu_{y, X}(u)$ "indicator value (output variable) $y(X)$ with a parameter value set $X=(0,6 ; 0,9)$ " (formula (6)), i.e the confidence degree that the option under consideration deserves an appropriate assessment.

Several approaches are proposed for obtaining the final evaluation [8-10]. Highlight two of them.

Table 5: Calculation of the membership degree of different values of the indicator, under the parameter values 0.6 and 0.9

\begin{tabular}{|l|c|c|c|c|c|c|c|}
\hline Indicator value & 2 & 2,5 & 3 & 3,5 & 4 & 4,5 & 5 \\
\hline$\mu_{\mathrm{C}_{12}}(\mathrm{x})$ & 0 & 0,2 & 1,0 & 0 & 0 & 0 & 0 \\
\hline$\mu_{\mathrm{C}_{13}}(x)$ & 0 & 0 & 0,2 & 0,6 & 1,0 & 0,5 & 0 \\
\hline$\mu_{\mathrm{C}_{22}}(\mathrm{x})$ & 1,0 & 0,5 & 0 & 0 & 0 & 0 & 0 \\
\hline$e=\left(\mu_{A_{2}}(0.6) \wedge \mu_{B_{1}}(0.9)\right) \wedge \mu_{\mathrm{C}_{12}}(x)$ & 0 & 0,2 & 0,5 & 0 & 0 & 0 & 0 \\
\hline$f=\left(\mu_{A_{3}}(0.6) \wedge \mu_{B_{1}}(0.9)\right) \wedge \mu_{\mathrm{C}_{13}}(x)$ & 0 & 0 & 0,1 & 0,1 & 0,1 & 0,1 & 0 \\
\hline$g=\left(\mu_{A_{2}}(0.6) \wedge \mu_{B_{2}}(0.9)\right) \wedge \mu_{\mathrm{C}_{22}}(x)$ & 0,2 & 0,2 & 0 & 0 & 0 & 0 & 0 \\
\hline$e \vee f \vee g$ & 0,2 & 0,2 & 0,5 & 0,1 & 0,1 & 0,1 & 0 \\
\hline
\end{tabular}

As an assessment, the "center of gravity" is used, i.e. the ratio of the sum of the products of the elements of the first row of Table 5 to the corresponding elements of its last row to the sum of the elements of its last row. For the considered problem, it is:

$$
\frac{2 \cdot 0,2+2,5 \cdot 0,2+3 \cdot 0,5+3,5 \cdot 0,1+4 \cdot 0,1+4,5 \cdot 0,1+5 \cdot 0}{0,2+0,2+0,5+0,1+0,1+0,1+0}=3
$$

Another approach is related to the choice of an estimate, with the maximum degree of confidence. It equals 3 (satisfactory).

\section{Discussion}

The proposed method is simple computationally and allows the decision-maker to look at the situation from a new point of view, which is very useful for deepening the level of understanding of the situation in question, and will allow simplifying the process of developing a decision to use the EMERCOM facilities for the elimination of emergency consequences .

\section{Conclusion}

Fuzzy problems of vector (multiobjective) optimization were considered, for example, in [13, 22-25]. The novelty of the proposed approach is to use the partial criteria of Mamdani's ideas to convolve, the new one is also the field of application of the theory in question. The authors confined themselves to the tasks solved in the interests of the Ministry of Emergency Situations. In our opinion, the use of the proposed approach for solving the tasks of other power and civil departments is of particular interest. It would be useful to consider problems with more than two particular criteria.

\section{References}

[1] Osnovy matematicheskogo modelirovaniya [Fundamentals of mathematical modeling]. Tutorial, VATT, St. Petersburg, 1996.

[2] Podinovskiy VV, Nogin VD (1982), Poreto-optimal'nye resheniya mnogokriterial'nykh zadach [Poreto-optimal solutions of multicriteria problems], Nauka, Moscow.

[3] Kini RL, Rayfa Kh (1981), Prinyatie resheniy pri mnogikh kriteriyakh: predpochteniya $i$ zameshcheniya [Decision-making under many criteria: preferences and substitutions.], Radio i svyaz', Moscow.

[4] Germeyer YuB (1971), Vvedenie $v$ issledovanie operatsiy [Introduction to the study of operations], Nauka, Moscow.

[5] Flegontov AV, Chernykh A, Klykov P (2015), The evaluation of the efficiency of control systems for organizational systems, 2015 International Conference on "Stability and Control Processes" in Memory of V.I. Zubov, 558-559.

[6] Vilkov VB, Chernykh AK (1965), Teoriya i praktika optimizatsii upravlencheskikh resheniy $v$ usloviyakh CHS na transporte: monografiya [Theory and practice of optimization of managerial decisions in emergency situations in transport: monograph.], SanktPeterburgskiy universitet GPS MCHS Rossii, St. Petersburg, 2016.

[7] Zadeh LA (1965), Fuzzy sets, Information and Control, 8, 338-353.

[8] Shtovba SD (2001), Vvedenie $v$ teoriyu nechetkikh mnozhestv $i$ nechetkuyu logiku [Introduction to the theory of fuzzy sets and fuzzy logic]., UNIVERSUM-Vinnitsa, Vinnitsa.

[9] Kofman A (1982), Vvedenie $v$ teoriyu nechetkikh mnozhest [Introduction to the theory of fuzzy sets], Radio i svyaz', Moscow.

[10] Yakhyaeva GE (2006), Nechetkie mnozhestva $i$ neyronnye seti [Fuzzy sets and neural networks], Binom, Moscow.

[11] Leonenkov AV (2005), Nechetkoe modelirovanie v srede MATLAB $i$ fuzzyTECH [Fuzzy modeling in an environment MATLAB i fuzzyTECH], BKHV-Peterburg, St. Petersburg.

[12] Zade L (1976), Ponyatie lingvisticheskoy peremennoy $i$ ego primenenie $k$ prinyatiyu priblizhennykh resheniy [The concept of a linguistic variable and its application to the adoption of approximate solutions], Mir, Moscow. 
[13] Orlovskiy SA (1981), Problemy prinyatiya resheniy pri nechetkoy iskhodnoy informatsii [Decision problems with fuzzy source information], Nauka; Glavnaya redaktsiya fiziko-matematicheskoy literatury, Moscow.

[14] Mamdani EH, Assilian S (1975), An experiment in linguistic synthesis with a fuzzy logic controller, International Journal of Man-Machine Studies, 7, 1-13.

[15] Kostygov AM, Dadenkov DA, Kaverin MA (2013), Nechetkaya sistema upravleniya dvizheniem mobil'nogo robota [Fuzzy traffic control system for a mobile robot], Sovremennye problemy nauki $i$ obrazovaniya, 5.

[16] Pegat A (2013), Nechetkoe modelirovanie i upravlenie [Fuzzy modeling and control], BINOM. Laboratoriya znaniy, Moscow.

[17] Terano T, Asai K, Sugeno M (1993), Prikladnye nechetkie sistemy [Applied fuzzy systems], Mir, Moscow.

[18] Karmanov VG (2004), Matematicheskoe programmirovanie [Mathematical programming], Izd-vo fiz.-mat. literatury, Moscow.

[19] Vagner G (1972), Osnovy issledovaniya operatsiy [Fundamentals of Operations Research], 1, Mir, Moscow.

[20] Taha HA (2005), Vvedenie $v$ issledovanie operatsiy [Operations Research: An Introduction] 7th edition, Translation from English, Izdatel'skiy dom "Vil'yams", Moscow.

[21] Degtyarev YuI (1986), Issledovanie operatsiy [Operations research], Vysshaya shkola, Moscow.

[22] Semenov BA, Ledeneva TM (2009), Mnogokriterial'naya optimizatsiya na osnove nechetkoy logiki [Multicriteria optimization based on fuzzy logic]. Sistemy upravleniya i informatsionnye tekhnologii, Nauch. kn, Voronezh, 1(35), 43-47.

[23] Zagranyan EV (2009), Mnogokriterial'naya zadacha nechetkoy maksimizatsii nezavisimykh kriteriev [Multicriteria problem of fuzzy maximization of independent criteria], Izvestiya Yuzhnogo federal'nogo universiteta Tekhnicheskie nauki, 5, 117-121.

[24] Malygin IG, Shirlin DV (2008), Upravlenie sovmestnymi deystviyami pozharno-spasatel'nykh podrazdeleniy pri likvidatsii transgranichnykh pozharov, avariy i katastrof na primere Rossii Finlyandii [Managing joint actions of fire and rescue units in the elimination of transboundary fires, accidents and disasters in the example of Russia and Finland] Nauchno-analiticheskiy zhurnal «Problemy upravleniya riskami $v$ tekhnosfere», 4(8), 114-125.

[25] Malygin IG (2004), Predlozheniya po sovershenstvovaniyu upravleniya razrabotkoy $i$ snabzheniem pozharnoy tekhnikoy Gosudarstvennoy protivopozharnoy sluzhby MCHS Rossii na osnove metodologii programmno-tselevogo planirovaniya [Proposals on improving the management of the development and supply of fire equipment of the State Fire Service of the Ministry of Emergencies of Russia on the basis of the methodology of programtargeted planning]. Nauchno-tekhnicheskiy zhurnal «Pozharovzryvobezopasnost», 2, 66-71. 